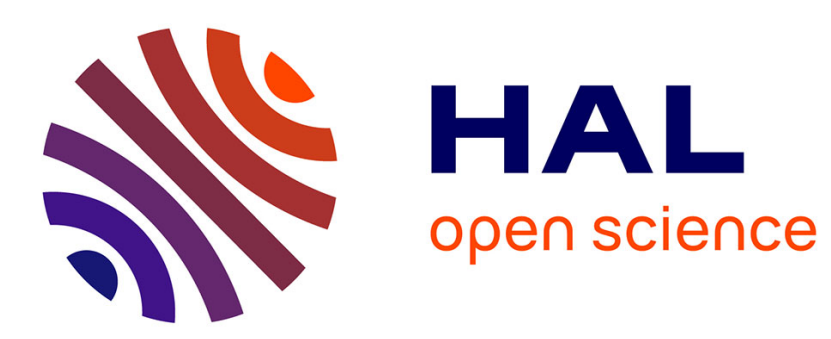

\title{
The role of configural information in facial emotion recognition in schizophrenia
}

Valerian Chambon, Jean-Yves Baudouin, Nicolas Franck

\section{To cite this version:}

Valerian Chambon, Jean-Yves Baudouin, Nicolas Franck. The role of configural information in facial emotion recognition in schizophrenia. Neuropsychologia, 2006, 44 (12), pp.2437-2444. 10.1016/j.neuropsychologia.2006.04.008 . hal-00561023

\section{HAL Id: hal-00561023 \\ https://u-bourgogne.hal.science/hal-00561023}

Submitted on 15 Apr 2011

HAL is a multi-disciplinary open access archive for the deposit and dissemination of scientific research documents, whether they are published or not. The documents may come from teaching and research institutions in France or abroad, or from public or private research centers.
L'archive ouverte pluridisciplinaire HAL, est destinée au dépôt et à la diffusion de documents scientifiques de niveau recherche, publiés ou non, émanant des établissements d'enseignement et de recherche français ou étrangers, des laboratoires publics ou privés. 


\title{
The role of configural information in facial emotion
}

\section{recognition in schizophrenia}

\author{
Valérian Chambon ; Jean-Yves Baudouin \&Nicolas Franck
}

The schizophrenia deficit in facial emotion recognition could be accounted for by a deficit in processing the configural information of theface. The present experiment was designed to further test this hypothesis by studying the face-inversion effect in a facial emotion recognitiontask. The ability of 26 schizophrenic patients and 26 control participants to recognize facial emotions on upright and upside-down faces wasassessed. Participants were told to state whether faces expressed one of six possible emotions (happiness, anger, disgust, fear, sadness, neutrality)in two sessions, one with upright faces and the other with upside-down faces. Discriminability and the decision criterion were computed. Theresults indicated that the schizophrenic patients were impaired in upright facial emotion discrimination by comparison with the controls. They alsoexhibited an inversion effect similar to the controls. However, whereas controls tended to adopt a more conservative criterion for all emotions anda liberal criterion for neutrality when the faces were upside-down, schizophrenic patients presented a decision criterion pattern that was similar forthe two orientations and similar to controls in upside-down emotion recognition. The lack of a decision criterion shift was associated with positivesymptoms such as delusions, hallucinations, and bizarre behavior. Moreover, positive and negative symptoms were associated with inversion effecton discriminability; the more severe the symptoms, the weaker the inversion effect.We conclude that individuals with schizophrenia do process theconfigural information of the face. However, further investigations are needed to assert whether this information is of good quality in schizophrenia.

\section{Introduction}

A broad range of deficits in interpersonal skills characterizeschizophrenia.Anaturalway to tackle these deficits is to explorethe ability of schizophrenic patients to process stimuli that havea wellestablished psychosocial content: faces, for instance. Inparticular, facial expressions are known as a powerful vectorof social interaction: when facial information processing isimpaired, the possibility for patients with schizophrenia toengage in proper interactions is jeopardized and their sense ofsocial worth is reduced (Walker, McGuire, \&Bettes, 1984).Deficits in facial emotion recognition and discrimination have been studied extensively, and most investigators have pointedout that schizophrenic patients perform less well than nonpatientsand psychiatric controls on facial emotion recognitiontests (e.g., Borod, Martin, Alpert, Brozgold,\&Welkowitz, 1993;Cutting, 1981; Mandal, 1986; Morrison, Bellack, \&Mueser,1988). The use of a differential design combining emotionaland non-emotional facial judgment tasks (i.e., control task)has also revealed the existence of additional deficits in facialrecognition, familiar and non-familiar face matching, and agerecognition (Archer, Hay,\&Young, 1992; Berndl, von Cranach,\&Grusser, 1986; Feinberg, Rifkin, Schaffer, \& Walker, 1986;Kerr \& Neale, 1993; Kohler, Bilker, Hagendoorn, Gur, \&Gur,2000). Furthermore, a significant correlation between abnormalperformance and negative and positive symptom subgroups hasbeen revealed in numerous studies, indicating that this deficitin facial emotion recognition is a function of symptom severity(Addington\&Addington, 1998; Kohler et al., 2000; Loughland,Williams, \& Gordon, 2002a; Schneider, Gur, Gur, \&Shtasel, 
1995).The abnormal performance of schizophrenic patients in facialrecognition tasks could be due to an inability to process andintegrate typical features that convey a social meaning or thatinvolve an affective appraisal (Frith, Stevens, Johnstone, Owens,\& Crow, 1983). Many recent studies have tried to relate thishypothesis with the incorrect information intake due, for example,to an abnormal visual scanning (Loughland et al., 2002a;Loughland, Williams, \& Gordon, 2002b; Manor et al., 1999;Streit,Wolwer, \&Gaebel, 1997;Williams, Loughland, Gordon,\& Davidson, 1999). Loughland et al. (2002a) addressed thepossibility that the schizophrenic deficit in facial emotion recognitionresults from a breakdown in the neurocognitive strategiesthat underlie the processing of face stimuli. Overall, this deficitmight reflect failure to integrate salient features, probably due todeficient local processing of relevant information and a dysfunctionin the networks that synchronize local and global processingof face stimuli. According to this account, the abnormal visualscanpath of schizophrenics reflects over reliance on sequentialvisual search strategies, perhaps to compensate for an earlierproblem in the configural processing of faces (e.g., relational orgestalt processing). Configural processing has been shown to becrucial for healthy participants to acquire facial expertise (for areview, see Maurer, Le Grand, \&Mondloch, 2002) and facialexpression recognition (Calder, Young, Keane, \& Dean, 2000).Schwartz, Rosse, Johri, and Deutsch (1999) reported that controlparticipants made more saccades of less than $50 \mathrm{~ms}$ to uprightthan to upside-down faces, and assumed that the processing ofconfigural information was disturbed for upside-down faces.Schizophrenic patients did not differ across face orientations. Therefore a specific disturbance in access to facial configuralinformation could account for the differences between thevisual scanpath of schizophrenics and that of healthy or psychiatricpatient controls. The restricted visual scanpaths reportedfor both emotion processing and face recognition may reflect atendency to pay more attention to some components of the faceand less attention to information on configuration (Loughlandet al., 2002a). On the other hand, Schwartz, Marvel, Drapalski,Rosse, and Deutsch (2002) reported observations indicating thatschizophrenic patients processed facial configural information. They observed a classic inversion effect for object recognitionand emotion recognition that tended to be stronger for facesthan for houses, as it was reported for healthy participants (Yin,1969). They also found a composite effect in face recognitionsimilar to the one reported with healthy participants by Young,Hellawell, and Hay (1987). In line with these results, Schwartz etal. (2002) concluded that the facial emotion processing deficit inschizophrenia cannot be accounted for by a deficit in configuralinformation processing.

The present experiment was designed to further test thishypothesis by studying the face-inversion effect in a facial emotionrecognition task. A set of photographs of expressive faceswas shown to 26 healthy participants and 26 schizophrenicpatients in two conditions, upright and upside-down. If theschizophrenic deficit in facial recognition does indeed resultfrom a problem in processing configural information, theninverting faces - which generally impairs this type of processing- should not disturb them as much as healthy participants.For instance, the performance of the schizophrenic group in theupside-down condition might differ little or not at all from theirperformance in the upright condition, suggesting that patientsdevelop the same analytic strategy for upright and upsidedownfaces. This strategy is essentially based on the processing of "componential information" (information about the physicalcharacteristics of the face's components).We then assessed participants'performance in emotional recognition: (i) for uprightfaces and (ii) the influence of inverting those faces on discriminabilitymeasures.We also looked at whether the recognition offacial emotions and the inversion effect were associated with aparticular symptomatology, i.e., whether 
performance was correlatedwith the severity of negative and/or positive symptomsof schizophrenia, as assessed by the Scale for the Assessmentof Negative Symptoms (SANS; Andreasen, 1983) and the Scalefor the Assessment of Positive Symptoms (SAPS; Andreasen,1984).

\section{Method}

\subsection{Participants}

Twenty-six patients with schizophrenia ( 6 females, 20 males; mean age:32.15 years, range 21-48) and 26 healthy participants ( 8 females, 18 males;mean age: 32.6 years, range $21-53$ ) volunteered to participate in the study.All patients were hospitalized at the Vinatier Psychiatric Hospital in Lyon,France. The patients subjects were recruited if their current diagnosis accordingto DSM-IV (American Psychiatric Association, 1994) criteria was schizophrenia, with no other psychiatric comorbidity on DSM-IV Axis I. Exclusion criteriaincluded visual difficulty, history of neurological illness or trauma, alcohol ordrug dependence according to DSM-IV criteria, and age older than 65 years.All patients were receiving antipsychotic medication (principally olanzapineand risperidone) and were clinically stable at testing time (mean illness duration:9.65 years, S.D. $=26$, range 2-28). SAPS (Andreasen, 1984) and SANS(Andreasen, 1983) were used to obtain ratings for positive and negative symptomsin the schizophrenia sample (the mean scores are presented in Table 1).None of the controls reported neurological diseases or psychiatric problems.They were matched with schizophrenic patients on sex, age, and years of education(see Table 1). All participants reported normal or corrected-to-normalvisual acuity. None of them was paid for taking part in the study.

\subsection{Materials}

The test materials consisted of 48 colored photographs of faces expressing 6 different emotions (happiness, fear, sadness, anger, disgust, and neutrality), with 8 photographs for each emotion. The photographs were of 29 females and 19 clean-shaven males, with no facial particularities (e.g., scars, eye glasses,jewellery).

Table 1

Demographic characteristics of patients and control participants: means \pm standard deviations (means (bold) \pm standard deviations (italic))

\begin{tabular}{lcc}
\hline & Schizophrenia & Controls \\
\hline Men & $\mathbf{2 0}$ & $\mathbf{1 8}$ \\
Women & $\mathbf{6}$ & $\mathbf{8}$ \\
Age (years) & $\mathbf{3 2 . 1} \pm 7.8$ & $\mathbf{3 2 . 6} \pm 11.8$ \\
Education (years) & $\mathbf{1 1 . 8} \pm 2.8$ & $\mathbf{1 2 . 9} \pm 2.6$ \\
Duration of illness (years) & $\mathbf{9 . 6} \pm 5.3$ & - \\
SANS $^{\mathrm{a}}$ score & $\mathbf{3 3} \pm 24.6$ & - \\
SAPS $^{\mathrm{b}}$ score & $\mathbf{4 4 . 6} \pm 17.3$ & - \\
\hline
\end{tabular}

${ }^{2}$ Scale for the Assessment of Negative Symptoms.

${ }^{\text {b }}$ Scale for the Assessment of Positive Symptoms.

The emotional valence of the faces was verified via a pretest onemotion category and intensity. For the pretest, a comparison group of elevenstudents was asked to say whether the photographed faces were happy, fearful,angry, sad, disgusted, neutral, or other. After having selected a category, theyhad to rate the intensity of the emotion from 0 to 10 . The photographs chosenfor use in the experiment were the ones that had been categorized in the sameemotional category by at least 10 of 
the participants, with an intensity of atleast 4.5 out of 10. ANOVAs revealed no significant difference between theemotions on percentage of choice or intensity (all $F_{S}<1$ ). All information aboutbackground and body was eliminated. The faces were $8.50 \mathrm{~cm}$ high and $6.20 \mathrm{cmwide}$ when presented on a computer monitor (19 in.). Short definitions of eachemotion derived from Ekman and Friesen (1971) were printed on a sheet ofpaper and given to the participants during the test.

\subsection{Procedure and design}

The experiment took place in two sessions. The participants were requiredto: (i) identify the emotion expressed on a set of 48 upright faces, and (ii) identifythe emotion expressed on a set of 48 upsidedown faces. The presentationorder of the 48 faces was randomly rearranged on each session, and the orderof the two sessions was alternated across participants: half of the participantscompleted the "upright" task first followed by the "upside-down" task, whilethe other half executed these two tasks in the opposite order. Every participantalways performed both tasks one after the other the same day, which involved 96emotional judgments in all. For both tasks, participants sat in front of the computermonitor at an approximate distance of $70 \mathrm{~cm}$. Patients and controls wereinstructed to respond aloud, as accurately and as quickly as possible (reactiontimes were not recorded, however). The experimenter entered the participant'sanswers on a computer connected to the test monitor.Each session began with a blank screen lasting three seconds. Next, afixation point appeared in the center of the screen and then disappeared afterone second. After a second blank screen lasting one second, the first faceappeared in the middle of the screen and remained there until the participantresponded. This exact sequence was run for each of the 48 faces in bothsessions.

\section{Results}

The mean response percentages in each experimental conditionare presented in Table 2. A visual inspection of this tablesuggests that there was some bias in the participants' responses.For example, the answer "neutral" was incorrectly given moreoften than the others, especially in the upside-down condition.So for each participant in each experimental condition, we computedthe $A_{-}$and $B_{-}$ indexes from signal detection theory (Grier,1971). The rationale for using these indexes is that when someparticipants tend to respond more often for a particular emotion(e.g., neutral), the false alarm rate ("neutral" answer for otheremotions) for that emotion will be high and the hit rate couldalso increase by comparison to other emotions. This means thata high percentage of correct recognitions for a given emotion canindicate either high accuracy or a bias toward that emotion. The $A_{-}$and $B_{\text {_ }}$ indexes take both hits and false alarms into account. $A$ is an index of discriminability; it indicates a participant's abilityto discriminate the target emotion among other emotions. $A_{-}$ranges from 0 to 1 , with 1 corresponding to the case where theparticipants recognized the emotion each time it was presented without "recognizing" it in other emotions and .5 correspondingto chance-level performance (i.e., the participant "recognized"the emotion as often on a face that really expressed that emotionas on faces that expressed another emotion). $B_{-}$is an indexof bias; it indicates the participant's decision criterion, whichcan be liberal (the participant has a tendency to "recognize" theemotion) or conservative (the participant has a tendency to notrecognize the emotion). $B_{-}$ ranges from -1 (liberal criterion) to 1 (conservative criterion), with the value 0 indicating a neutralcriterion. 
Table 2

Mean percentage of responses for each emotion on upright and upside-down facial emotions, by group

\begin{tabular}{|c|c|c|c|c|c|c|c|}
\hline \multicolumn{2}{|l|}{ Group } & \multicolumn{6}{|c|}{ Response } \\
\hline Orientation & Emotion & Happy & Angry & Disgusted & Fearful & Sad & Neutral \\
\hline \multicolumn{8}{|l|}{ Controls } \\
\hline \multirow[t]{6}{*}{ Upright } & Happiness & 98.1 & .0 & .0 & .5 & .0 & 1.4 \\
\hline & Anger & .0 & 81.7 & 9.1 & 3.4 & 4.8 & 1.0 \\
\hline & Disgust & .5 & 5.8 & 85.1 & 1.9 & 4.8 & 1.9 \\
\hline & Fear & 4.3 & 1.0 & 2.4 & 90.4 & .5 & 1.4 \\
\hline & Sadness & .0 & 1.0 & 4.8 & 4.3 & 85.1 & 4.8 \\
\hline & Neutrality & 3.8 & 1.0 & .0 & .5 & 8.2 & 86.5 \\
\hline \multirow[t]{6}{*}{ Upside-down } & Happiness & 95.2 & .0 & 2.4 & .0 & 1.0 & 1.4 \\
\hline & Anger & 3.4 & 66.8 & 4.3 & 1.0 & 1.4 & 22.6 \\
\hline & Disgust & 5.8 & 8.7 & 68.8 & 1.0 & 11.5 & 4.3 \\
\hline & Fear & 2.9 & 1.0 & 1.0 & 75.5 & 2.4 & 17.3 \\
\hline & Sadness & 1.9 & 2.4 & 5.8 & 2.9 & 35.6 & 51.0 \\
\hline & Neutrality & 9.6 & 1.0 & 1.4 & .5 & 8.7 & 78.4 \\
\hline \multicolumn{8}{|c|}{ Schizophrenic patients } \\
\hline \multirow{4}{*}{ Upright } & Happiness & 90.4 & .5 & .5 & .0 & 2.9 & 5.8 \\
\hline & Anger & 4.3 & 70.2 & 10.6 & 1.4 & 5.3 & 8.2 \\
\hline & Disgust & 9.1 & 12.0 & 55.8 & 5.3 & 12.5 & 5.3 \\
\hline & Enene & 67 & 52 & 87 & $\angle \mathbf{e}$ & 10 & 87 \\
\hline \multirow[t]{6}{*}{ Jpright } & Happiness & 90.4 & .5 & .5 & .0 & 2.9 & 5.8 \\
\hline & Anger & 4.3 & 70.2 & 10.6 & 1.4 & 5.3 & 8.2 \\
\hline & Disgust & 9.1 & 12.0 & 55.8 & 5.3 & 12.5 & 5.3 \\
\hline & Fear & 6.7 & 5.3 & 8.7 & 68.8 & 1.9 & 8.7 \\
\hline & Sadness & 1.0 & 1.4 & 13.9 & 5.8 & 68.3 & 9.6 \\
\hline & Neutrality & 4.8 & 1.0 & 2.4 & 1.0 & 10.6 & 80.3 \\
\hline \multirow[t]{6}{*}{ Upside-down } & Happiness & 82.2 & 1.4 & 2.4 & 1.0 & 1.0 & 12.0 \\
\hline & Anger & 9.6 & 51.4 & 8.7 & 3.4 & 4.3 & 22.6 \\
\hline & Disgust & 15.4 & 6.7 & 44.7 & 5.3 & 19.7 & 8.2 \\
\hline & Fear & 7.2 & 4.8 & 5.3 & 53.4 & 5.8 & 23.6 \\
\hline & Sadness & 8.2 & 3.8 & 7.2 & 7.2 & 21.6 & 51.9 \\
\hline & Neutrality & 6.3 & 3.8 & 2.9 & 3.4 & 5.3 & 78.4 \\
\hline
\end{tabular}

Bold values correspond to the correct response.

\subsection{Discriminability (A」)}

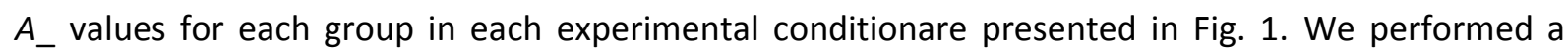
$\log (10)$ transformon these values and then input them into a $2 \times 2 \times 6$ ANOVA with group (schizophrenic patients versus controls) asa between-subject factor, and orientation (upright versus upsidedown)and emotion (happiness versus anger versus disgustversus fear versus sadness versus neutrality) as within-subjectfactors. The main effect of group was significant; the discriminabilityof emotions was lower for schizophrenic patients than for controls(.85 versus .93, $F(1,50)=14.03, p<$ .001). The main effectof orientation was also significant, with lower discriminabilityfor emotions on upside-down than on upright faces (.85 versus.93, $F(1,50)=61.36, p<.0001$ ). The interaction between orientationand group was not significant $(F(1,50)=1.39)$, indicatinga similar orientation effect for both schizophrenic patients andcontrols. Moreover, the interaction between orientation, emotion, and groupwas not significant $(F(5,250)=1.34)$, suggestingthat the orientation effect was similar for schizophrenic patientsand controls, whatever the emotion. The main effect of emotion was significant $(F(5,250)=17.58, p<.0001)$, but it was qualified by an interactionbetween emotion and orientation $(F(5,250)=12.48, p<.0001)$. Linear comparisons indicated that orientation had a significanteffect on all emotions (lowest $F: F(1,50)=4.55, p<.05$ ), but) for emotions on upright faces, by emotion, orientation, and group different extents. Discriminability dropped the most for sadness(difference between upright and upside-down faces $=.20$ ), followedby neutrality (difference $=.07$ ), anger (difference $=.06$ ), disgust (difference $=.05$ ), fear (difference $=.04$ ), and happiness(difference $=.03$ ). The interaction between emotion and group was also significant $(F(5$, $250)=2.78, p<.05)$. Linear comparisons indicatedthat emotion discriminability was lower for 
schizophrenicpatients than for controls, for all emotions (lowest $F: F(1,50)=7.17, p<.05$ ) except neutrality $(F(1,50)=1.87)$. The lackof an interaction between orientation, emotion, and group (seeabove) suggests that this pattern was similar for emotion onupright and upside-down faces.The significant interaction between emotion and group in theprevious analysis, combined with the lack of a significant interactionbetween orientation, emotion, and group, indicated that:(i) the difference between schizophrenic patients and controlswas not the same for all emotions, and (ii) this difference patternwas similar for the two orientations. In order to determinewhether schizophrenic patients have a different deficit for differentemotions, we performed a $2 \times 6$ ANOVA on the $A$ values forupright faces only, with group (schizophrenic patients versuscontrols) as a between-subject factor and emotion (happinessversus anger versus disgust versus fear versus sadness versusneutrality) as a within-subject factor. $A_{\text {_ }}$ values for upside-downfaces were not included in the analysis because our purposewas to test the deficit in emotion recognition for schizophrenicpatients. Despite a nonsignificant interaction, data for upsidedownfacial emotion could have contaminated some effects, i.e.,some effect could be significant or not only because of theirinclusion in the analysis. The main effects of group $(F(1,50)=10.72, p<.01)$ and emotion $(F(5,250)=6.82, p<.0001)$ were both significant, but theywere qualified by a significant interaction between group andemotion $(F(5,250)$ $=3.44, p<.01)$. Linear comparisons indicatedthat the emotion effect was non-significant for controls $(F(5,250)=.81)$ but was significant for schizophrenic patients $(F(5,250)=9.45, p<.0001)$. For the schizophrenics, linear contrastsshowed that the discriminability of happiness (.96)was significantlyhigher than for the other emotions $(F(1,50)=40.36, p<.0001)$, and the discriminability of disgust (.82) was significantlylower than for the other emotions $(F(1,50)=11.82, p<.01)$. Anger (.91), fear (.89), sadness (.88), and neutrality(.90) did not differ significantly $(F(3,150)=.94)$. When weconsidered the group effect for each emotion, the discriminabilitywas lower for schizophrenic patients than for controls oneach emotion (lowest $F: F(1,50)=7.06, p<.05)$ except neutrality $(F(1$, $50)=3.08)$. For the emotions, the difference betweencontrols and schizophrenic decreased in the following order:disgust (.13), fear and sadness (.07), anger (.04), and happiness(.03).To summarize, emotions were: (i) less discriminable forschizophrenic patients than for controls, and (ii) less discriminablewhen the faces were upside-down. The decrease inemotion discriminability on upsidedown faces was greater forsadness, and also neutrality. Moreover, this inversion effectwas similar for the two groups of participants, suggesting thatschizophrenic patients are impaired to the same extent as controls, and for the same emotions.

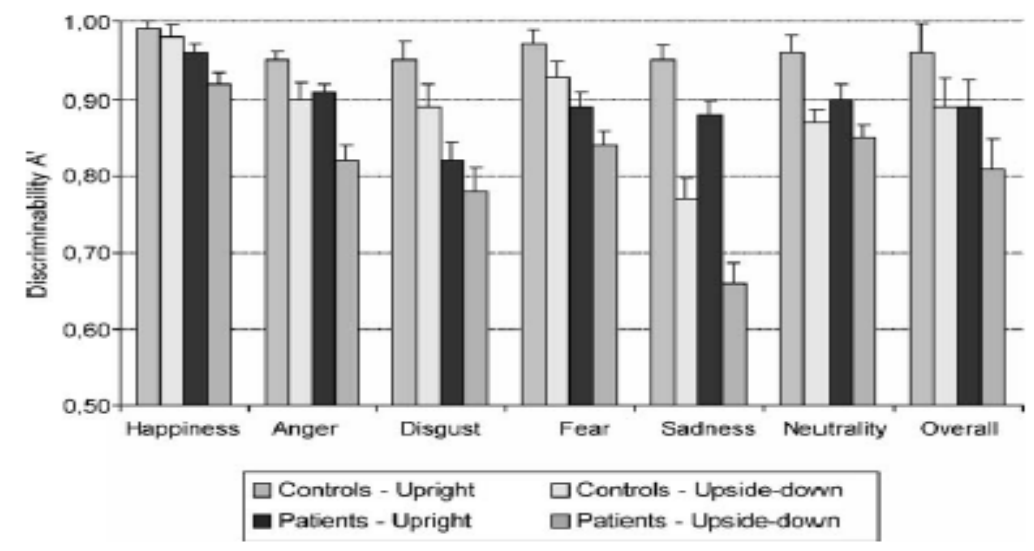

Fig. 1. Discriminability $\left(A^{\prime}\right)$ for emotions on upright faces, by emotion, orientation, and group (error bars correspond to standard errors). 


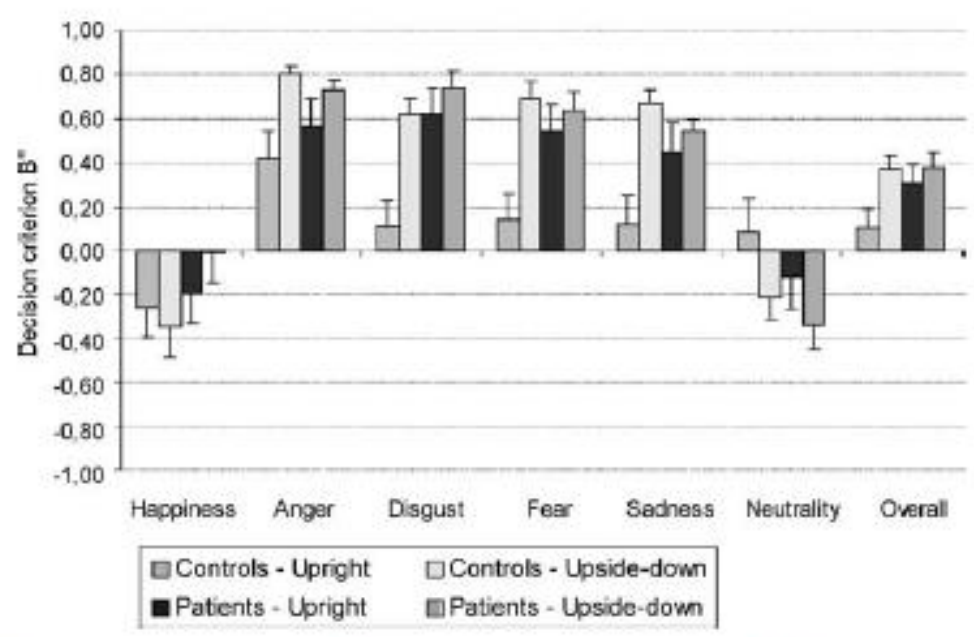

Fig. 2. Decision criterion $\left(B^{\prime \prime}\right)$ for emotions on upright faces, by emotion, orientation, and group (error bars correspond to standard errors).

\subsection{Decision criterion (B_}

The $B_{\text {_ }}$ values for each group in each experimental conditionare presented in Fig. 2 . We performed a $\log (10)$ transform onthese values after having added 10 to each one. Then, we analyzedthem in a $2 \times 2 \times 6$ ANOVA with group (schizophrenicpatients versus controls) as a between-subject factor, and emotion(happiness versus anger versus disgust versus fear versussadness versus neutrality) and orientation (upright versusupside-down) as within-subject factors. The main effect of group was significant; the criterion wasmore conservative for schizophrenic patients than for controls(.35 versus $.24, F(1,50)=10.59, p<.01)$. The main effect oforientation was also significant, with a more conservative criterionfor upside-down than for upright faces $(.38$ versus $.21, F(1,50)=32.80, p<$ .0001). The interaction between orientation andgroup was also significant $(F(1,50)=10.53, p<.01)$, indicatingan orientation effect for controls, whose criterion was moreconservative for upside-down faces (.37 versus .10 for uprightfaces, $F(1,50)=40.24, p<0001$ ), but not for schizophrenicpatients $(.38$ versus $.31, F(1,50)=3.08)$. Thus, the criterion wasmore conservative for schizophrenic patients than for controlswhen the faces were upright $(.31$ versus $10, F(1,50)=16.31, p<.001)$, but not when they were upside-down $(.38$ versus $.37, F(1,50)=.16)$. The main effect of emotion was significant $(F(5,250)=30.60, p<.0001)$, but it was qualified both by an interactionbetween emotion and orientation $(F(5,250)=5.30, p<.001)$, and by an overall interaction between emotion, orientation, and group $(F(5,250)=2.34, p<.05)$. The post hoc LSDof Fisher test $(p<.05)$ indicated that, for controls recognizingupright facial emotions, the criterion was liberal for happiness(-.26), and neutral to conservative for the other emotions (from.09 to .42), with significant differences between happiness andthe other emotions. The criterion was also significantly moreconservative for anger (.42) than for neutrality (.09), disgust(.11), and sadness (.12). No other differences were significant. When the faces were upside-down, the criterion was liberal forboth happiness (-.35) and neutrality (-.21), but conservativefor the other emotions (from .62 to .80). All of the differencesbetween liberal and conservative criteria were significant, butno differences within each set were significant. When the criteriafor upright and upside-down faces were contrasted, controlsadopted a significantly more conservative criterion for negativeemotions on upside-down faces, and a significantly more liberalcriterion for neutrality, with a non-significantly different criterionfor happiness. Whatever the orientation, schizophrenic patients tended toadopt the same 
criteria that controls recognizing upside-downfacial emotion. When the groups were contrasted on uprightfaces, schizophrenic patients had a significantly more conservativecriterion for disgust, fear, and sadness. The other differenceswere non-significant. For upside-down faces, the onlysignificant difference was for happiness, with controls usinga liberal criterion (-.35) and schizophrenic patients using amore neutral criterion $(-.01)$. Interestingly, the criterion wasnot different for controls recognizing upright emotions andschizophrenic patients recognizing upside-down emotions, nomatter what emotion was expressed on the face. When the criteriafor upright and upside-down facial emotions were contrastedfor schizophrenic patients, none of the differences were significant, i.e., the criterion was not significantly modified byinversion, whatever the emotion.In sum, whereas controls exhibited a more conservative criterionfor upside-downthan upright facial emotions, schizophrenicpatients adopted the same criterion for both orientations, whichwas equal to the conservative criterion used by controls forupside-down facial emotions. Looking at the criteria by emotionshowed that controls recognizing upright emotions adopteda liberal criterion for happiness and a neutral-to-conservative criterionfor the other emotions. After inversion, controls adopteda more conservative criterion for negative emotions and a moreliberal criterion for neutrality. Schizophrenic patients did notchange their criterion after inversion. More interestingly, theytended to adopt the same criterion pattern for upright and upsidedownfacial emotions as the controls did for upside-down emotions;i.e., a conservative criterion for negative emotions and aliberal one for neutrality and happiness.

3.3. Correlations between SAPS/SANS scores or subscoresand discriminability ( $A\lrcorner$ ) or the decision criterion (B_ forschizophrenic patients

In order to find out if the impaired performance ofschizophrenic patients is associated with the severity of theirsymptoms, we computed Spearman coefficients of correlationbetween their scores and subscores on the SANS and SAPSscales (Andreasen, 1983, 1984), their discriminability and decisioncriterion indexes for upright and upside-down facial emotions,and the inversion effect. The inversion effect on discriminabilitywas computed by subtracting discriminability forupside-down facial emotions from discriminability for uprightfacial emotions; the greater the difference, the stronger was

\begin{tabular}{|c|c|c|c|c|c|c|}
\hline \multirow[t]{2}{*}{ SAPS and SANS scores and subscores } & \multicolumn{2}{|c|}{ Upright } & \multicolumn{2}{|c|}{ Upside-down } & \multicolumn{2}{|c|}{ Inversion } \\
\hline & $A^{\prime}$ & $B^{\prime \prime}$ & $A^{\prime}$ & $B^{\prime \prime}$ & $A^{\prime}$ & $B^{\prime \prime}$ \\
\hline $\begin{array}{l}\text { SAPS } \\
\text { Hallucinations } \\
\text { Delusions } \\
\text { Bizarre behavior } \\
\text { Thought disorder }\end{array}$ & $\begin{array}{l}-.45^{\mathrm{a}} \\
-.57^{\mathrm{b}} \\
-41^{\mathrm{a}} \\
-.48^{\mathrm{a}} \\
-.10\end{array}$ & $\begin{array}{l}.47^{\mathrm{a}} \\
.52^{\mathrm{b}} \\
.45^{\mathrm{a}} \\
.34 \\
.28\end{array}$ & $\begin{array}{r}-.17 \\
-.35 \\
-.13 \\
-.30 \\
.09\end{array}$ & $\begin{array}{r}-.12 \\
-.14 \\
-.16 \\
.32 \\
-.12\end{array}$ & $\begin{array}{l}-.42^{\mathrm{a}} \\
-.42^{\mathrm{a}} \\
-.48^{\mathrm{a}} \\
-.02 \\
-.26\end{array}$ & $\begin{array}{l}-.58^{\mathrm{b}} \\
-.58^{\mathrm{b}} \\
-.61^{\mathrm{b}} \\
-.03 \\
-.44^{\mathrm{a}}\end{array}$ \\
\hline $\begin{array}{l}\text { SANS } \\
\text { Affective flattening } \\
\text { Alogia } \\
\text { Avolition/apathy } \\
\text { Anhedonia/associability } \\
\text { Attention }\end{array}$ & $\begin{array}{l}-.23 \\
-.33 \\
-.10 \\
-.11 \\
.00 \\
-.52^{\mathrm{b}}\end{array}$ & $\begin{array}{r}-.06 \\
.11 \\
-.11 \\
-.19 \\
.05 \\
.08\end{array}$ & $\begin{array}{r}.02 \\
-.02 \\
.09 \\
-.09 \\
.13 \\
-.18\end{array}$ & $\begin{array}{l}-.17 \\
-.13 \\
-.06 \\
-.10 \\
-.31 \\
-.02\end{array}$ & $\begin{array}{l}-.39^{\mathrm{a}} \\
-.45^{\mathrm{a}} \\
-.27 \\
-.18 \\
-.26 \\
-.46^{\mathrm{a}}\end{array}$ & $\begin{array}{r}-.08 \\
-.24 \\
.05 \\
.13 \\
-.29 \\
-.08\end{array}$ \\
\hline
\end{tabular}

the interference due to inversion. The inversion effect on thedecision criterion was computed by subtracting the decisioncriterion for upright facial emotions from the decision criterionfor upsidedown facial emotions; the greater the difference,the stronger the shift to a conservative criterion after inversion.The coefficients of correlation are reported in Table 3 (see alsoFig. 3).The SAPS scores 
co-varied significantly and negatively withdiscriminability of emotions on upright faces and with inversion, but not with discriminability of emotions on upside-downfaces.
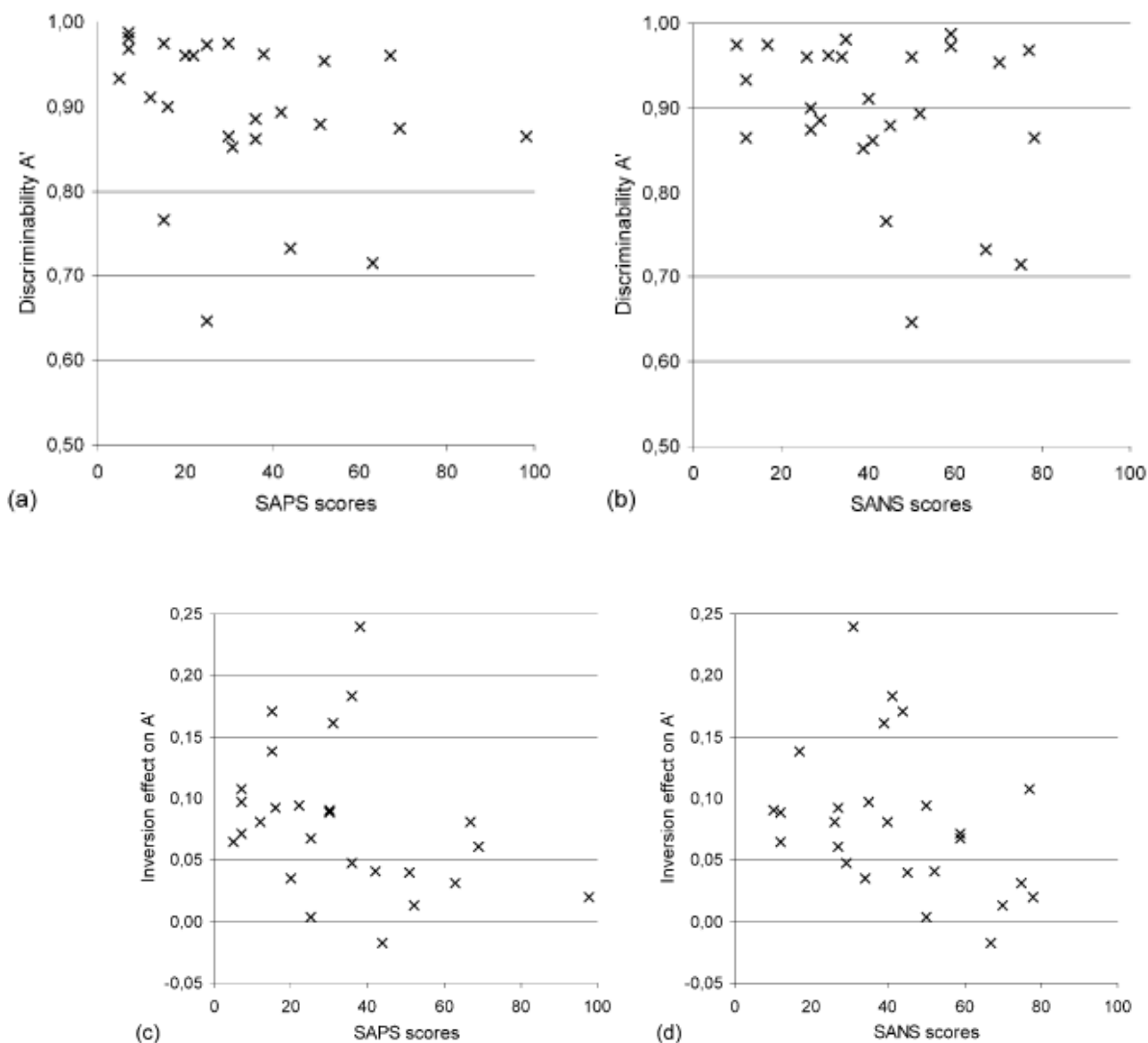

Fig. 3. Scatterplots of discriminability $A^{\prime}$ and SAPS scores (a), discriminability $A^{\prime}$ and SANS scores (b), inversion effect on discriminability $A^{\prime}$ and SAPS scores (c), and inversion effect on discriminability $A^{\prime}$ and SANS scores (d).

Thus, the more the patients exhibited positive symptoms, the less the emotions were discriminable and the less the inversioneffect was strong. The subscore coefficients indicated thatthe discriminability of upright facial emotions and the inversioneffect were mainly associated with delusions and hallucinationsin both orientations, but also with bizarre behavior for uprightfacial emotions. For the decision criterion, the SAPS scoresco-varied with both the decision criterion on upright facial emotions(but not upside-down ones) and inversion. Schizophrenicpatients who tended to have more severe positive symptomsalso tended to adopt a more conservative criterion for uprightfacial emotions. An increase in the severity of positive symptomswasalso associated with a lesser tendency to shift to a moreconservative criterion after inversion. Analysis of the subscoresindicated that, as above for discriminability, these associationsmainly concerned hallucinations and delusions. The only co-variation with theSANSscoreswas the inversioneffect on discriminability; the more severe the negative symptoms,the weaker the inversion effect. The subscores neverthelessindicated that both upright discriminability and inversion covariedwith attention deficits.Thus, the deficit in facial emotions discriminability inschizophrenia, as well as the absence of a decision criterionshift after inversion, appears to be mainly linked to the positivesymptom severity. More particularly, patients who tendedto discriminate emotions less easily also experienced more hallucinationsand delusions, and exhibited more bizarre behaviors. The 
emotion discriminability deficit was also associated withan attentional deficit. Moreover, correlation analyses on discriminabilitymeasures showed that, despite an inversion effectsimilar to that of controls when they were considered as a group(see previous results), schizophrenic patients who tended to havemore severe negative and positive symptoms also tended to havea weaker inversion effect.

\section{Discussion}

The results of the present study replicated earlier observationsindicating that schizophrenic patients are impaired in facial emotionprocessing. This impairment concerns all emotions, even ifsome notably disgust - appear to be altered more than others. Thus, schizophrenic patients do not have a specific deficit forcertain emotions only although the severity of the deficit variedacross emotions. Schizophrenic patients also differed fromcontrols in their decision criterion; they adopted a more conservativecriterion overall, which means they tended to say "no"when they had to match a perceptual emotion stimulation to itscorresponding mental representation. The criteria they adoptedfor the different emotions also differed considerably from that ofcontrols (in fact, it corresponded to the criteria used by controlswhen recognizing upside-down emotions), with a liberal criterionfor happiness and neutrality, and a conservative criterionfor negative emotions.Consideration of the symptomatology further indicated thatthe deficit in emotion recognition was not associated with asingle kind of symptom. Overall, no link between this deficitand negative symptoms was observed in the present study, butsome subscores (e.g., attention) of the SANS scale were correlatedwith the magnitude of the deficit. The role of attention inschizophrenia has been well documented in the literature (e.g.,Addington\&Addington, 1998). It has been proposed that anattention deficit may be a cause of schizophrenic patients' deficitin face processing: schizophrenics are thought to not pay attentionto relevant facial information and be hindered by other facialinformation (Baudouin, Martin, Tiberghien, Verlut, \& Franck,2002; Bediou et al., 2005; Martin, Baudouin, Tiberghien, \&Franck, 2005). This suggests that the various kinds of facialinformation are not extracted automatically but need attention. The attention deficit of schizophrenics would therefore generatetheir face processing impairment. A strong associationbetween the deficit and positive symptoms was also found inthe present study. In particular, emotion discriminability andthe shift to a more conservative criterion for upside-down facialemotions were lower when hallucinations, delusions, and bizarrebehaviors were more prominent and higher in the oppositecase. Thus, it appears that some symptoms may result from (orcause?) the deficit in emotion recognition. Notably, the difficultiesschizophrenic patients have in recognizing facial emotions, and their tendency to not recognize negative emotions, may favorthe emergence of socially inadapted behavior, like hallucinations, delusions, and bizarre behaviors.Regarding the configural processing of emotions, the resultsshowed first that schizophrenic patients were as disturbed byinversion as controls, and also to the same extent. Thus, no particulardisturbance for schizophrenic patients was evidenced withdiscriminability indexes. However, both the decision criterionanalyses and correlation analyses modulated this conclusion.Based on the decision criterion, we found that, overall, controlsadopted a more conservative criterion for assessing emotionson upside-down faces. When the emotions were analyzed separately,we saw that inversion resulted in a more conservative criterionfor negative emotions, but a more liberal criterion for neutrality.Thus, the tendency of controls to respond "no" to negativeemotions and "yes" to neutrality was accentuated by face inversion. The disruption of configural processing brought about byface inversion seems to have caused controls to change their 
decisioncriterion. This change was not observed for schizophrenicpatients, who exhibited the same decision criterion pattern forthe two orientations. Moreover, their pattern was similar to thatof controls when recognizing upside-down facial emotions. Inshort, for upright emotions, schizophrenic patients acted as ifconfigural information processing was disrupted, in the sameway as controls did after inversion. Correlation analyses furthershowed that the size of the inversion effect for discriminabilitywas modulated by both positive and negative symptoms. Moreparticularly, schizophrenic patients with higher subscores of hallucinations,delusions, affective flattening, and attention deficitswere less sensitive to inversion. So, the greater the severity ofthese symptoms, the lower the sensitivity to configural information.This last observation suggests that schizophrenic patientswith more severe symptoms tended to process both upright andupside-down faces in the same way, i.e., componentially.A possible explanation to these observations could be thatschizophrenic patients do in fact process configural information, but in an incorrect way. It has been reported that some prosopagnosicpatients (patients who are unable to recognize a personfrom their face) process configural information but incorrectly(e.g., De Gelder\&Rouw, 2000). In this case, the problem doesnot result from the absence of configural processing but from thefact that the configural information extracted is of poor quality.In schizophrenia, an abnormal pattern of exploration of faces hasbeen reported (e.g., Streit et al., 1997;Williams et al., 1999), aswell as a composite effect (Schwartz et al., 2002). One can thushypothesize that schizophrenic patients extract configural information, and that such information will automatically interferewith the processing of local part of the face. This could explainboth the composite effect and the inversion effect reported bySchwartz et al. (2002), and the inversion effect in emotion recognitionin the present study. Nevertheless, configural informationwould not need to be of good quality to interfere; we can suppose, indeed, that even low quality configural information willinfluence the processing of local parts of faces (see De Gelder\&Rouw, 2000). So, we could hypothesize that the extracted configuralinformation will be of low quality in schizophrenia, dueto an inappropriate exploration of faces. Schizophrenic patientswould then rely more on other kind of information (e.g., localor componential information) to recognize facial emotions. Thisassumption, however, remains to be tested.

\section{Acknowledgments}

This work was supported by an ACl "JeunesChercheuseset JeunesChercheurs 2003" grant (No. 6056) from the FrenchMinistry of Research awarded to Jean-Yves Baudouin. All participantsgave their informed consent to participate in the study, which was performed in accordance with the ethical standardslaid down in the 1964 declaration of Helsinki. We gratefullyacknowledge Professor JeanLouis Terra and his clinical stafffor their collaboration and use of facilities. We wish to thankCoralieChevallier for her assistance in proofreading this paperas well as the two anonymous reviewers for their helpful commentsand suggestions.

\section{References}

Addington, J., \&Addington, D. (1998). Facial affect recognition and informationprocessing in schizophrenia and bipolar disorder. SchizophreniaResearch, 32, 171-181.

Andreasen, N. C. (1983). The Scale for the Assessment of Negative Symptoms(SANS). lowa City, IA: The University of lowa. 
Andreasen, N. C. (1984). The Scale for the Assessment of Positive Symptoms(SAPS). lowa City, IA: The University of lowa.

Archer, J., Hay, D. C., \& Young, A. W. (1992). Face processing in psychiatricconditions. British Journal of Clinical Psychology, 31, 45-61.

Baudouin, J.-Y., Martin, F., Tiberghien, G., Verlut, I., \& Franck, N. (2002). Selective attention for facial identity and emotional expression in schizophrenia. Neuropsychologia, 40, 518-526.

Bediou, B., Franck, N., Saoud, M., Baudouin, J.-Y., Tiberghien, G., Dalery, J., et al. (2005). Effects of emotion and identity on facial affect processing in schizophrenia. Psychiatry Research, 133, 149-157.

Berndl, K., von Cranach, M., \&Grusser, O. J. (1986). Impairment of perception and recognition of faces, mimic expression and gestures in schizophrenic patients. European Archives of Psychiatry and NeurologicalSciences, 235, 282-291.

Borod, J. C., Martin, C. C., Alpert, M., Brozgold, A., \&Welkowitz, J. (1993).

Perception of facial emotion in schizophrenic and right brain-damaged patients. Journal of Nervous and Mental Diseases, 181, 494-501.

Calder, A. J., Young, A. W., Keane, J., \& Dean, M. (2000). Configuralinformation in facial expression perception. Journal of Experimental Psychology:Human Perception and Performance, 26, 527-551.

Cutting, J. (1981). Judgement of emotional expression in schizophrenics. British Journal of Psychiatry, $139,1-6$.

De Gelder, B., \&Rouw, R. (2000). Paradoxical configuration effects for faces and objects in prosopagnosia. Neuropsychologia, 38, 1271-1279.

Ekman, P., \& Friesen, W. V. (1971). Constant across cultures in the face and emotion. Journal of Personality \& Social Psychology, 49, 1753-1761.

Feinberg, T. E., Rifkin, A., Schaffer, C., \& Walker, E. (1986). Facial discrimination and emotional recognition in schizophrenia and affective disorders. Archives of General Psychiatry, 43, 276-279.

Frith, C. D., Stevens, M., Johnstone, E. C., Owens, D. G. C., \&Crow, T. J. (1983). Integration of schematic faces and other complex objects in schizophrenia. Journal of Nervous and Mental Disease, 171, 34-39.

Grier, J. B. (1971). Nonparametric indexes for sensitivity and bias: Computing formulas. Psychological Bulletin, 75, 424-429.

Kerr, S. L., \& Neale, J. M. (1993). Emotion perception in schizophrenia: Specific deficit or further evidence of generalized poor performance? Journalof Abnormal Psychology, 702, 312-318.

Kohler, C. G., Bilker, W., Hagendoorn, M., Gur, R. E., \&Gur, R. C. (2000). Emotion recognition deficit in schizophrenia: Association with symptomatology and cognition. Biological Psychiatry, 48, 127-136.

Loughland, C. M., Williams, L. M., \& Gordon, E. (2002a). Visual scanpathto positive and negative facial emotions in an outpatient schizophrenia sample. Schizophrenia Research, 55, 159-170. 
Loughland, C. M., Williams, L. M., \& Gordon, E. (2002b). Schizophreniaand affective psychosis show different visual scanpath strategies for faces:A trait versus state-based distinction? Biological Psychiatry, 52, 338- 348.

Mandal, M. K. (1986). Judgement of facial affect among depressive and schizophrenics. British Journal of Clinical Psychology, 25, 87-92.

Manor, B. R., Gordon, E., Williams, L. M., Rennie, C. J., Bahramali, H., Latimer, C. R., et al. (1999). Eye movements reflect impaired face processing in patients with schizophrenia. Biological Psychiatry, 46, 963-969.

Martin, F., Baudouin, J.-Y., Tiberghien, G., \& Franck, N. (2005). Processing of faces and emotional expression in schizophrenia. Psychiatry Research, 134, 43-53.

Maurer, D., Le Grand, R., \&Mondloch, C. J. (2002). The many faces of configural processing. Trends in Cognitive Sciences, 6, 255-260.

Morrison, R. L., Bellack, A. S., \&Mueser, K. T. (1988). Deficits in facial affect recognition and schizophrenia. Schizophrenia Bulletin, 14, 67-83.

Schneider, F., Gur, R. C., Gur, R. E., \&Shtasel, D. L. (1995). Emotional processing in schizophrenia: Neurobehavioural probes in relation to psychopathology. Schizophrenia Research, 17, 15-61.

Schwartz, B. L., Marvel, C. L., Drapalski, A., Rosse, R. B., \& Deutsch, S. I. (2002). Configural processing in face recognition in schizophrenia. Cognitive Neuropsychiatry, 7, 15-39.

Schwartz, B. L., Rosse, R. B., Johri, S., \& Deutsch, S. I. (1999). Visual scanning of facial expressions in schizophrenia. Journal of Neuropsychiatryand Clinical Neurosciences, 11, 103-106.

Streit, M., Wolwer, W., \&Gaebel, W. (1997). Facial-affect recognition and visual scanning behaviour in the course of schizophrenia. SchizophreniaResearch, 24, 311-317.

Walker, E., McGuire, M., \&Bettes, B. (1984). Recognition and identification of facial stimuli by schizophrenics and patients with affective disorders. British Journal of Clinical Psychology, 23, 37-44.

Williams, L. M., Loughland, C. M., Gordon, E., \& Davidson, D. (1999). Visual scanpaths in schizophrenia: Is there a deficit in face recognition? Schizophrenia Research, 40, 189-199.

Yin, R. K. (1969). Looking at upside-down faces. Journal of Experimental Psychology, 81, 141-145.

Young, A. W., Hellawell, D., \& Hay, D. C. (1987). Configurational information in face perception. Perception, 16, 747-759. 